\title{
Numerical Modelling of Prefabricated Vertical Drain for Soft Clay using ABAQUS
}

\author{
Saiful Azhar Ahmad Tajudin ${ }^{1, a,}$ Mohd Fairus Yusof ${ }^{2 *}$, b, Ismail Bakar ${ }^{3}$, \\ Aminaton Marto ${ }^{4}$, Muhammad Nizam Zakaria ${ }^{5}$, Mohd Ezree Abdullah ${ }^{6}$ \\ 1,2,3,5,6 Faculty of Civil and Environmental Engineering, Universiti Tun Hussein Onn Malaysia \\ ${ }^{4}$ Faculty of Civil Engineering, Universiti Teknologi Malaysia \\ asaifulaz@uthm.edu.my, ${ }^{b}$ fairus@uthm.edu.my*
}

Keywords: Prefabricated Vertical Drain, Soft Clay, Settlement, Consolidation, ABAQUS.

\begin{abstract}
Construction, buildings and infrastructure founded on soft clays are often affected by settlement problem. Therefore, Prefabricated Vertical Drain (PVD) is one of the best solutions to accelerate soil consolidation by shortening the drainage path. In this study, numerical investigation was carried out to pursue a better understanding of the consolidation behavior of soft clay improved with PVD. The consolidation process accelerated by PVD with surcharge of $50 \mathrm{kPa}$ was analysed using the ABAQUS software by adopting an elastic model. The aim of this study is to compare the settlement and the required time to fully consolidate the soft soil at different drain spacings $(1.0 \mathrm{~m}$, $1.5 \mathrm{~m}$ and $2.0 \mathrm{~m}$ ) for two different thickness of the clay layer. The results shows that the time required to completely consolidate the soft soil for $12 \mathrm{~m}$ and $20 \mathrm{~m}$ thickness of clay layer with different spacings are in the range of 3 months to 66 months. The settlement rate and excess pore water pressure dissipation are increased when the spacing of the drain closer.
\end{abstract}

\section{Introduction}

An increasing proportion of building development takes place in areas of poor ground and this poses challenges for the Geotechnical engineers to provide satisfactory foundation performance at low cost. Construction, buildings and infrastructure founded on soft clays are often affected by the stability and settlement problems. A proportion of the final settlement can be achieved prior to construction by preloading the soil, but this often takes 6 to 9 months or more to achieve [1]. The larger the preload, the time to achieve the final settlement will be decreased. PVD combined with surcharge may be a cost-effective way in reducing the post settlement due to lightly distributed loads from roads or residential buildings.

Prefabricated vertical drains are band shaped (rectangular cross-section) product consisting of a geotextile filter material surrounding a plastic core. The size of PVD is typically $10 \mathrm{~cm}$ wide by 3 to $4 \mathrm{~mm}$ in thickness [2]. The material consist of a plastic core to create channels which are wrapped in a geotextile filter. The main function of the filter of the vertical drain is to ensure that fine particles cannot pass through and clogging the drainage channels in the core [3]. PVD is installed vertically into the soil to let the water flow from the weak soil underground to the surface, in order to speed up the consolidation process. After the consolidation process was completed in a certain period of time, the roads, dikes, runways, railways, or any structures can be safely constructed on the ground.

The aim of vertical drain installation is to shorten the drainage paths of water and thereby reduce the time required to consolidate the soil which induced by surcharge load. The effectiveness of the vertical drain installation depends on the drain spacing and the discharge capacity of the drains [4]. In soil improvement works, vertical drains only accelerate the primary consolidation process of the subsoil and they do not reduce the secondary consolidation. Therefore, surcharging has to be used in conjunction with vertical drains to reduce post-surcharge secondary compression. 


\section{Drain Properties}

Diameter of Influence Zone. The influence zone of vertical drain can be described as the coverage area of water movement towards the drain. The zone can be determined by drains spacing and installation pattern as proposed by Hansbo [3]. There are two common patterns in the installation of PVD which are square and triangular and the diameter of the influence zone can be determined by the following equation. For square pattern, $D_{e}=1.13 \mathrm{~S}$ and for triangular pattern, $D_{e}=1.05 \mathrm{~S}$ where $\mathrm{D}_{\mathrm{e}}$ is diameter of influence zone and $\mathrm{S}$ is the drain spacing. To obtain faster consolidation time triangular pattern could be used, however the square pattern installation is easier to perform.

Equivalent Diameter of Rectangular Vertical Drain. Most PVD are produced in the factory in rectangular cross-section to facilitate the storage, transportation and installation. However, in the conventional theory, the PVD is assumed to consolidate in radial direction. So, for design purposes, the width (w) and the thickness (h) of the PVD need to be converted into a equivalent circular with a diameter of $d_{w}$. There are many researchers proposed the conversion equation, but their results is almost similar. The following typical equation [3] can be used to determine the equivalent drain diameter:

$$
d_{\mathrm{w}}=2(\mathrm{w}+\mathrm{h}) / \pi
$$

Smear Effect. As the installation of PVD is usually carried out by a statically or sometime vibratory driven mandrel, the degree of disturbance to the surrounding soil is related to the size and shape of the mandrel as well as to the size of the detachable shoe or anchor. The disturbed zone around the drain is called smear zone. Due to the disturbance, the permeability and the preconsolidation pressure of the soil are reduced, and the compressibility increases. The decrease in horizontal permeability is most significant. For most of the soft clay, silt and organic soil, the ratios of $k_{\mathrm{h}} / k_{\mathrm{v}}$ are generally less than 3 . For marine clay with the homogeneous deposit environment, the ratio of $k_{\mathrm{h}} / k_{\mathrm{v}}$ is around 1 to 1.5 ; for lacustrine clay, varved clay and clays with discontinuous lenses and layers of more permeable materials, the ratios of $k_{\mathrm{h}} / k \mathrm{v}$ are in the range of 2 to $5[5,6]$.

\section{Methodology}

The single unit of circular PVD was modelled using ABAQUS software with different drain length. Due to their circular shape of influence zone, the axisymmetric model was used for analysis. The soil parameters used for modelling purposes is shown in Table 1. Three models with varying spacing $(1.0 \mathrm{~m}, 1.5 \mathrm{~m}$ and $2.0 \mathrm{~m})$ and two models with different drain lengths $(12 \mathrm{~m}, 20 \mathrm{~m})$ have been developed. The radius of equivalent drain was calculated based on the equation proposed by Hansbo [3], while the radius of smear zone determination is based on proposed correlation as suggested by Bergado et al. [6]. A two-dimensional axisymmetric mesh was used. The element chosen was a four-node axisymmetric quadrilateral element with bilinear displacement and bilinear pore pressure variations. For the boundary condition, the vertical and horizontal displacements were fixed at the bottom part of the model. For left and right side of the model, the horizontal displacement was also fixed to simulate the frictionless interface between the soil model and adjacent soil. The geostatic command was used to make sure that equilibrium is uniform within the clay layer. The consolidation pressure of $50 \mathrm{kPa}$ has been selected for the model to simulate the surcharge load (3 m height) with the bulk unit weight of $16 \mathrm{kN} / \mathrm{m}^{3}$. 
Properties

Table 1: Properties used in the models

\begin{tabular}{lc}
\hline Density, $\rho$ & $1835 \mathrm{~kg} / \mathrm{m}^{3}$ \\
\hline Young's Modulus, E & $30000 \mathrm{kN} / \mathrm{m}^{2}$ \\
\hline Poisson ratio, $v$ & 0.25 \\
\hline Void ratio, $\mathrm{e}$ & 1.2 \\
\hline Coefficient of permeability of the PVD, $\mathrm{k}_{\mathrm{w}}$ & $1.0 \times 10^{-3} \mathrm{~m} / \mathrm{s}$ \\
\hline Coefficient of permeability of the smear zone, $\mathrm{k}_{\mathrm{s}}$ & $0.6 \times 10^{-9} \mathrm{~m} / \mathrm{s}$ \\
\hline Coefficient of permeability of the undisturbed zone, $\mathrm{k}_{\mathrm{h}}$ & $1.8 \times 10^{-9} \mathrm{~m} / \mathrm{s}$ \\
\hline Radius of equivalent drain, $\mathrm{r}_{\mathrm{w}}$ & $0.03 \mathrm{~m}$ \\
\hline Radius of influence zone, $\mathrm{r}_{\mathrm{e}}$ & $0.53 \mathrm{~m}, 0.79 \mathrm{~m} \mathrm{\&} 1.05 \mathrm{~m}$ \\
\hline Radius of smear zone, $\mathrm{r}_{\mathrm{s}}$ & $0.09 \mathrm{~m}$ \\
\hline
\end{tabular}

\section{Results and Discussions}

To investigate the effect of PVD installation spacing and thickness of soft clay, three different drain spacings were considered in the analysis. Figure 1 (a) and 1 (b) show the rate of settlement with different drain spacings for clay layer thickness of $12 \mathrm{~m}$ and $20 \mathrm{~m}$ respectively.

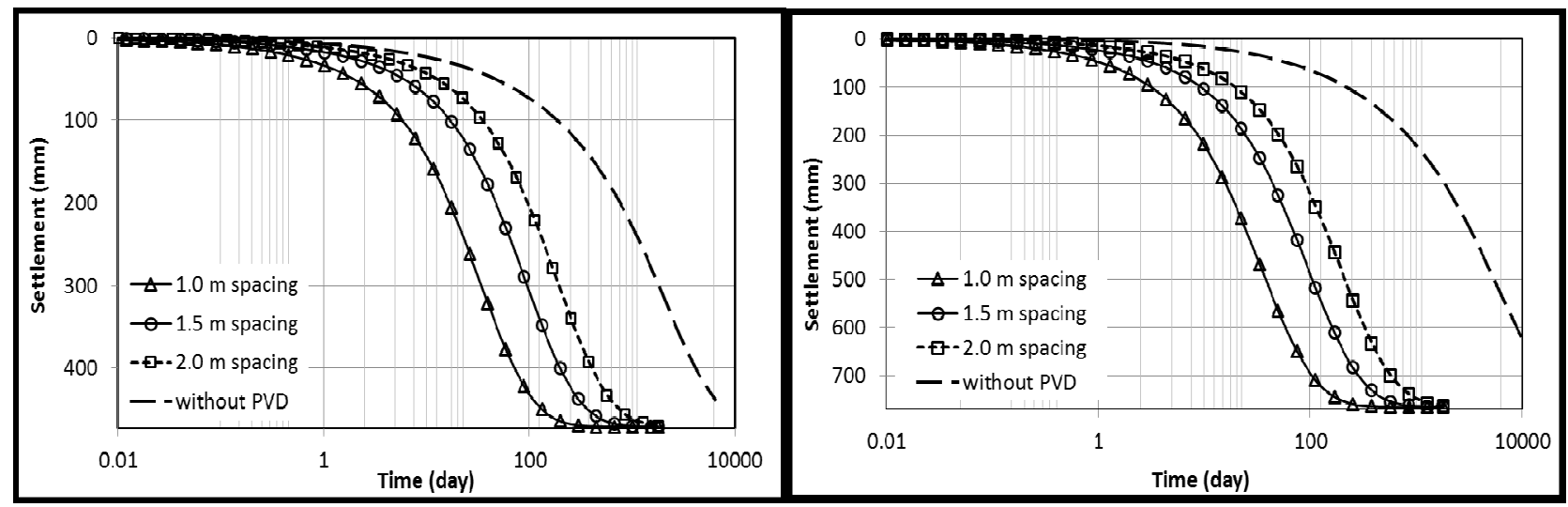

(a)

(b)

Figure 1: The settlement of various drain spacing with different thickness of soft clay (a) $12 \mathrm{~m}$ soft clay thickness (b) $20 \mathrm{~m}$ soft clay thickness

The primary settlement for the model with $1.0 \mathrm{~m}$ spacing end within a short period of time compared with $1.5 \mathrm{~m}$ and $2.0 \mathrm{~m}$ spacing for both thickness as shown in Fig. 1. In addition, the rates of settlements are increasing with the decreasing of drain spacing for both length of PVD due to the decreasing of the horizontal drainage path. In terms of the thickness of soft clay, the rate of settlements for $12 \mathrm{~m}$ and $20 \mathrm{~m}$ of the drain length were also compared to the settlement without PVD. From the graph it can be seen that, the rate of settlements of soft clay without PVD for both lengths were lower than those with PVD at different spacings. The primary settlement of soft clay improved with PVD are considerably faster than the model without PVD. The total settlement of the soft clay with the thickness of $12 \mathrm{~m}$ and $20 \mathrm{~m}$ are $480 \mathrm{~mm}$ and $770 \mathrm{~mm}$ respectively but the time to achieve that settlement is different with different drain spacing.

As shown in Fig. 2, the degree of consolidation without PVD for $12 \mathrm{~m}$ and $20 \mathrm{~m}$ lengths take approximately more than 9000 days (300 months) to complete which is longer than the model with PVD installation. Degree of consolidations is also completed $(100 \%)$ at a short period of time for both lengths when drainage spacings were reduced. The degree of consolidation for all spacings are same between $12 \mathrm{~m}$ and $20 \mathrm{~m}$ length of PVD. Therefore, the length of PVD has little or no effect on the consolidation time for all spacings. The magnitude of settlement at the smaller spacing could 
attribute to the smear effect [7]. Thus, this has caused greater disturbance to the soil when PVDs were installed at the closer spacing. The greater settlement observed in the zone with smaller drain spacing could also be due to the secondary compression. The soil would reach the virgin consolidation range earlier when the rate of consolidation increased which caused the secondary compression to develop earlier at a higher rate [8]. If the completion time is the most important design consideration, another way to reduce the consolidation time is to use a larger than required surcharge to consolidate the soil.

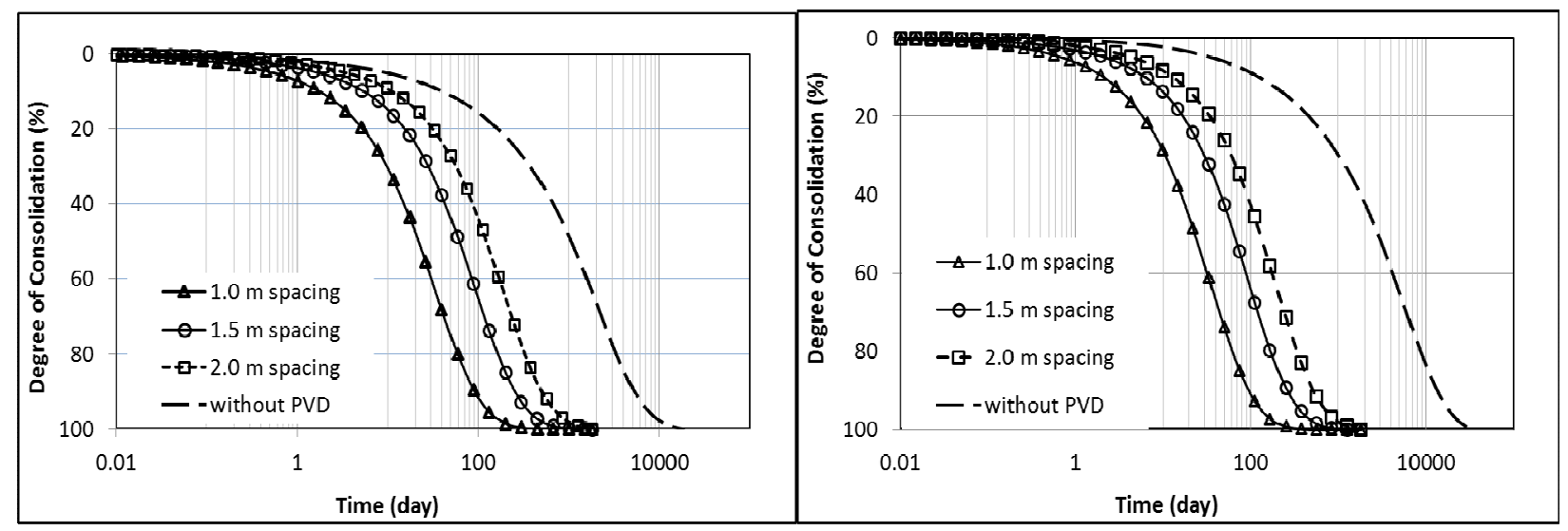

(a)

(b)

Figure 2: Degree of consolidation (a) $12 \mathrm{~m}$ drain length (b) $20 \mathrm{~m}$ drain length.

The $1.0 \mathrm{~m}, 1.5 \mathrm{~m}$ and $2 \mathrm{~m}$ spacing had achieved a $100 \%$ degree of consolidation in the range of 100 days (3 months) to 2000 days (66 months) for both lengths of PVD as compared to without PVD which has about more than 9000 days (approximately 300 months). It clearly shows that the time required to reach $100 \%$ degree of consolidation is much shorter if the PVD is being used as compared to without PVD. The water flows of this model are one-way drainage which is the top of the drain boundary. The different value of permeability at the drain, smear zone and undisturbed zone are related to the flow of water into the drain during the consolidation process. Movement of water from the model become slower and take longer time, particularly at the bottom of the model, where the water flows above the drain boundary (top of the model). Fig. 3 illustrates that at three different spacings, the excess pore pressures were decreased with time and the length of drains. The excess pore water pressure has increased between 10 to $20 \mathrm{kPa}$ initially and decreased at $0 \mathrm{kPa}$ after certain periods of time. The dissipation of excess pore water pressure was ceased about 200 days, 400 days and 800 days for drain spacing of $1.0 \mathrm{~m}, 1.5 \mathrm{~m}$ and $2.0 \mathrm{~m}$ spacings respectively. Due to the radial flow and similar equivalent radius, it is clearly shows that the both lengths of PVD have no significant effect in term of the excess pore water pressure trend. 


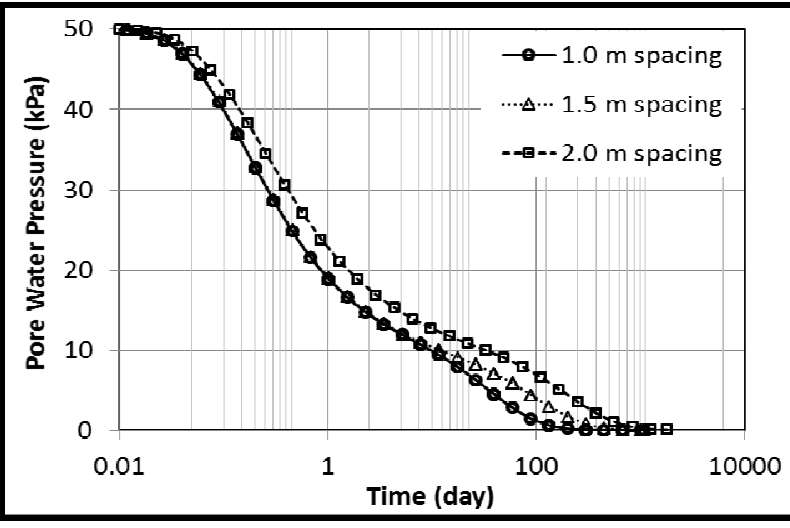

(a)

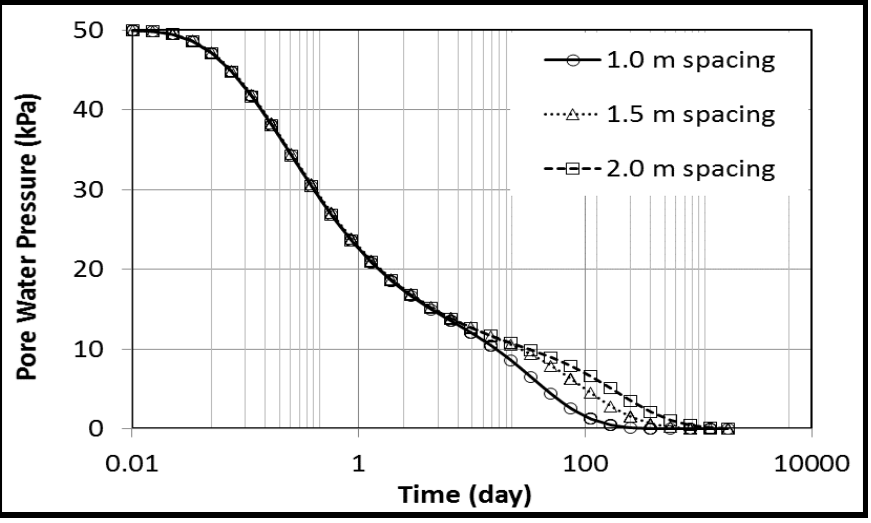

(b)

Figure 3: Excess pore water pressure dissipation (a) $12 \mathrm{~m}$ drain length (b) $20 \mathrm{~m}$ drain length.

\section{Conclusions}

In this paper, a numerical design and analysis for vertical drains incorporating with $50 \mathrm{kPa}$ surcharge was developed for axisymmetric modelling in different length $(12$ and $20 \mathrm{~m})$ and with different spacing $(1.0 \mathrm{~m}, 1.5 \mathrm{~m}$ and $2.0 \mathrm{~m})$ and also compared with and without PVD. After the analysis, the settlement, degree of consolidation and excess pore water pressure are reliable and comparable with past studies. Installation of the PVD significantly increased the rate of settlements with the decreased of drain spacing for 12 and $20 \mathrm{~m}$ length of PVD. For the excess pore water pressure for $12 \mathrm{~m}$ and $20 \mathrm{~m}$ length with different spacings, it can be concluded that the closer the drain spacing, the dissipation of excess pore water pressure is faster. Therefore, an effective drainage system and proper design are the key for success of ground improvement by a surcharge with PVD installation.

\section{Acknowledgements}

The authors also would like to thank the Ministry of Higher Education, Malaysia for supporting this research under the Exploratory Research Grant Scheme (ERGS) Vot. E040.

\section{References}

[1] J.A. Charles and K.S. Watts, Treated ground: engineering properties and performance, London: Construction Industry Research and Information Association, CIRIA Funders Report/C572, (2002).

[2] M. W. Bo, J. Chu, B. K. Lo, and V. Choa, Soil Improvement: Prefabricated Vertical Drain Techniques, Thomson, (2003), pp. 341. ISBN: 981-243-044-X.

[3] S. Hansbo, Consolidation of fine-grained soils by prefabricated drains, In Proceedings of 10th International Conference on Soil Mechanics and Foundation Engineering, Stockholm, Balkema, Rotterdam, 3, (1981), pp. 677-682.

[4] S. Hansbo, Experience of consolidation process from test areas with and without vertical drains". Ground Improvement - Case Histories Book (Volume 3), Edited by Indraratna, B. and Chu, J., Elsevier, London, Chapter 1, (2005), pp. 3-49.

[5] G. Mesri, and D.O.K. Lo, Field Performance of Prefabricated Vertical Drains, Proceeding International Conference on Geotechnical Engineering for Coastal Development-Theory to Practice, Yokohama, Japan, Vol. 1, (1991), pp 231-236. 
[6] D. T. Bergado, H. Asakami, M. C. Alfaro and A.S. Balasubramaniam, Smear effects of vertical drains on soft Bangkok clay, J. Geotech. Eng., ASCE, 117(10), (1991), pp.1509-1530.

[7] J. Saowapakpiboon, D.T. Bergado, P. Voottipruex, L.G. Lam, K. Nakakuma, PVD improvement combined with surcharge and vacuum preloading including simulations, Geotextiles and Geomembranes, 29 (1) (2011), pp. 74-82

[8] M.W. Bo, J. Chu, V. Choa, The Changi east reclamation project in Singapore. In: Indraratna B, Chu J (eds) Ground improvement: case histories. Geo-Engineering Book Series 3, Elsevier, Amsterdam, (2005), pp 247-27 